\title{
0 mais originário do Dasein: o lidar prático no mundo
}

\author{
The most primordial of Dasein: the practical relationship in the world
}

Rafael Ribeiro Almeida ${ }^{1}$

1 Graduando em filosofia pela Universidade Estadual de Santa Cruz - ILHÉUS, BA, Brasil

E-mail: estudosrafael@gmail.com

RESUMO: Na década de 20 do século passado, época do aparecimento de Ser e tempo, Heidegger posicionase veementemente contra o modelo teórico-cognitivo de sujeito-objeto, problematizando, assim, a hegemonia da teoria do conhecimento na filosofia. Contra este paradigma, o filósofo alemão traz à tona um modo original de abordar a lida mais primária do Dasein no mundo, cuja primazia recai em um sentido prático, por assim dizer. Neste sentido, nosso objetivo reside em explicitar, a partir do pensamento heideggeriano, a relação mais primária que o Dasein estabelece com o mundo, a saber: uma relação de familiaridade práticooriginária. Para tanto, investiga-se o pensamento de Martin Heidegger em sua primeira fase, notadamente a sua obra-mestra: Ser e tempo, de 1927. Na obra, o filósofo alemão explicita que o mundo que preliminarmente se apresenta ao Dasein e com o qual ele se relaciona não é de ordem teórica, no sentido de relação cognoscitiva, mas, isto sim: é o da práxis cotidiana, da postura prática, isto é, o mundo circundante, no qual o Dasein, enquanto ser-no-mundo de compreensão pré-teórica, dispensa a postura temática explícita como secundária - isto é, derivada, portanto, não fundamental da constituição humana. Neste sentido, nota-se que o ser-nomundo, conforme indica Ser e tempo, consiste em um empenho prático, por isso mais originário, guiado por uma visão circundante que contempla a articulação de entes intramundanos os quais formam, no limite, um contexto no qual o mundo circundante se anuncia.

Palavras-chave: Ser-no-mundo; Mundo circundante; Compreensão.

ABSTRACT: In the twenty-last century, at which time Being and Time was published, Heidegger stands extremely against the theoretical-cognitive model of subject-object, thus questioning the predominance of the theory of knowledge in Philosophy. Against this paradigm, the german philosopher expounds in an original way the most primary relation of Dasein in the world, in which priority refers to a practical sense. Thus, our aim is to explain, from Heideggerian thought, the most primary relation that Dasein establishes with the world, that is: a relation of familiarity primordial-practical. Therefore, we will investigate the thought of Martin Heidegger in his first phase, specifically his main book: Being and Time (1927). In this book, the german philosopher explains that the world that primarily presents itself to Dasein and with which it relates is not theoretical in the sense of a cognitive relation, but, on the contrary, it is the world of everyday praxis, of practical behaviour, that is, the environment in which Dasein, as being-in-the-world of pre-theoretical understanding, dispenses the theoretical behaviouras as secondary - that is: derived, therefore, not fundamental of the human constitution. Therefore, we can see that being-in-the-world, as show in the Being and Time, it consists in a practical behavior, and therefore even more primordial, guided by a circumspection that involves (contemplates) the articulation of entities within-the-world that establish among themselves, in the last instance, a context in which the environment announces itself.

Keywords: Being-in-the-world; Environment; Understanding. 


\section{CONSIDERAÇÕES INICIAIS}

Segundo Benedito Nunes (2004), o tratado de Ser e tempo revolucionou a tradição filosófica ocidental. E não apenas pelo peculiar formato expositivo da obra, imerso em termos novos, ou em termos com sentidos novos; sua radicalidade também reside na referência da economia interna da obra à existência "prática" do ente humano, retirando da filosofia, assim, a hegemonia da teoria do conhecimento. Os anos entre 1923 e 1927, época do aparecimento de Ser e tempo, são um período de incrível produtividade para o livre professor de filosofia de Marburg, Martin Heidegger, período em que ele lutou veementemente contra o modelo de relação teórica sujeito-objeto. Assim, dentro desse maciço trabalho intelectual - mil e quinhentas páginas na edição original -, o tratado de Ser e tempo, entre seus temas desenvolvidos, abre caminho para a investigação do ente humano enquanto um ser-no-mundo cujo empenho, primariamente, está prático. Isto é: a (pré) compreensão enquanto familiaridade prático-originária que o ente que nós mesmos somos tem com o mundo - eis o mais originário.

Neste sentido, pretende-se explicitar a forma originária de Martin Heidegger de abordar a lida mais primária do Dasein no mundo, cuja primazia recai em um sentido prático. Para tanto, investiga-se o pensamento heideggeriano em sua primeira fase, notadamente a sua obra-mestra: Ser e tempo, de 1927. Na obra, o filósofo alemão situa a relação mais primária que o Dasein estabelece com o mundo como uma relação de familiaridade prático-originária. Para o Heidegger de Ser e tempo, o mundo que preliminarmente se apresenta ao Dasein e com o qual ele se relaciona não é de ordem teórica, no sentido de relação cognoscitiva, mas, isto sim: é o da práxis cotidiana, da postura prática, isto é, o mundo circundante, no qual o Dasein, no seu lócus de ser-no-mundo de compreensão pré-teórica, dispensa como secundário uma postura temática explícita. Com isso, pretende-se evidenciar que o ser-no-mundo, como indica Ser e Tempo, consiste em um empenho prático, por isso mais originário, guiado por uma visão circundante que contempla a articulação de entes intramudanos os quais formam um conjunto contextual no qual o mundo circundante se anuncia.

Na primeira parte (Dasein: a familiaridade prático-originária no mundo), pretende-se explicitar que a relação mais primária que o Dasein trava com o mundo não é da ordem contemplativa, no sentido de relação cognoscitiva. O mundo que preliminarmente se apresenta ao Dasein é o da práxis cotidiana (da ação prática), isto é, o mundo circundante, no qual o ser-no-mundo [in der-Welt-sein] manifesta uma relação instrumental com os entes intramundanos que servem para isso ou para aquilo. Assim sendo, o termo circunvisão [Umsicht] aparece como conceito chave do empenho prático do Dasein no mundo: grosso modo, diz respeito a uma visão de conjunto. Quer dizer, guiada por uma visão de conjunto, a circunvisão assume um sentido de "olhar prático" para os instrumentos que se entrelaçam e que se articulam formando, em última instância, uma totalidade instrumental (mundo). Além disso, pretende-se do mesmo modo trazer à tona o conceito de compreensão [Verstehen]; ressalta-se, pois, que não se trata de uma compreensão de ordem teórico-conceitual e sim no sentido de familiaridade prático-originária com o mundo (condição pré- reflexiva e pré-teórica). Tendo em vista a (pré) compreensão enquanto familiaridade originária que o Dasein tem com o mundo, só se sabe "para quê" serve determinado ente intramundano uma vez que o Dasein já se encontra com ele e imerso dentro de um determinado contexto instrumental pertinente à serventia deste ente. Nota-se, portanto, a primazia do empenho prático-originário do Dasein na lida com o ente disponível [Zubanden].

$\mathrm{Na}$ segunda parte ( $A$ definição do ente bumano como cura), examina-se a estrutura mais originária e elementar do Dasein, a saber: o fenômeno da cura [Sorgen]. Consoante a esta estrutura mais básica do Dasein, destaca-se a atitude do ente que nós mesmos somos como primariamente "prática", e não cognitiva ou 
teórica. Corrobora-se este sentido ao explicitar o empenho veementemente prático presente nos modos "ocupação" e "preocupação", os quais são, por excelência, constitutivos da cura.

\section{O LIDAR PRÁTICO NO MUNDO: ESCLARECIMENTOS CONCEITUAIS}

O que significa "prática”? O que caracteriza algo como "prático”? Tendo em vista que a palavra em questão comporta um sentido especialmente amplo, e, por isso mesmo, vago, em nosso trabalho faz-se necessário, em primeiro lugar, uma delimitação do que se deve entender por "prática" quando nos valermos desse termo - afinal, trata-se de um termo-chave para o escopo do presente artigo.

De acordo com o Dicionário de Filosofia, de autoria de José Ferrater Mora:

o conceito do prático é fundamental em toda filosofia para a qual a prática é parte integrante do pensamento filosófico e inclusive o fundamento de todo pensar. Muito se discutiu a chamada 'relação entre a teoria e a prática', com frases tais como 'a prática segue à teoria', 'a prática determina (orienta, condiciona, etc.) a teoria', 'isso está bem na teoria, mas não na prática', etc. (MORA, 2000, p. 2345)

Consoante a citação (acima), a tradição filósofica comporta uma acepção de "prática" em termos de contraposto ao que é "teórico". Nesse raciocínio, pode-se tomar, por exemplo, determinado sistema de ideias (conceitos, proposições, etc) como próprio do âmbito teórico, e, por outro lado, tomar a aplicação (a ação) concreta de semelhante sistema a situações concretas como própria do âmbito prático.

Mas, afinal, de que "prática" se refere nosso texto? Em primeiro momento poder-se-ia pensar, quem sabe, que a proposta de nosso trabalho consiste em indicar como Heidegger confere primazia à lida prática no mundo em detrimento do teórico; quer dizer, Heidegger, nesse caso, realizaria simplesmente uma inversão do pensamento moderno de acordo com o qual a contemplação teórica está como modo fundamental da relação do ser-humano com o mundo. Afirmar que Ser e tempo confere uma primazia à relação prática (para com o mundo) no sentido acima da palavra "prática" (isto é: um âmbito distinto do teórico), sugere que o autor simplesmente empreende uma mudança de pólos, sem problematizar, porém, a legitimidade de tais pólos. Ledo engano, porém.

Com efeito, o sentido acima da palavra prática nada tem a ver com a expressão utilizada a partir do contexto heideggeriano especialmente o de Ser e tempo. Para Heidegger, o Dasein apresenta atitude primariamente prática no mundo enquanto condição pré-teórica, pré-categorial, pré-conceitual, quer dizer, a dinâmica de relacionamento do ser-aí com o mundo se dá, fundamentalmente, não enquanto apreensão teórica dos entes disponíveis ("conhecimento" que visa as propriedades entitativas dos entes), mas sim relaciona-se pré-compreensivamente com os entes que vem ao encontro. Compreensão, neste sentido, indica não uma tematização teórica de tais entes, mas sim a familiaridade-prática que o Dasein tem com o mundo. Deste modo, ao assinalar a primazia da relação prática do ser-aí no mundo, o presente texto procura destacar, com isso, o caráter mais básico e elementar do Dasein no mundo - o que está em jogo aqui: "compreender uma situação assim como ela é 'dada', antes mesmo de a tornar tema da investigação ou reflexão" (SAFRANSKI, 2000, p. 136).

Nas palavras de Ernildo Stein, a noção de prática aqui assume o seguinte sentido: 
não há experiência se não houver uma experiência, isto é, se não houver algo que nós já sempre experimentamos, mas que não podemos descrever como experiência porque nos escapa. É o chão originário é o lugar onde algo caiu, onde algo se estabeleceu, mas que não se recupera. A possibilidade de recuperar nossas experiências deve-se a esse lugar primeiro. [...] É claro que isso fica bem abstrato, mas nós de certa maneira podemos representar assim: há um chão criado por algo que aconteceu, que foi vivido, mas que é apenas condição de possibilidade de todas as experiências (STEIN, 2004, p. 31)

Prática, então, está no sentido de (pré) compreensão enquanto familiaridade originária que o Dasein tem com o mundo (conforme explicitaremos adiante com maior rigorosidade), ou seja, a noção em questão designa o lugar originário da experiência do Dasein no mundo, ou, para usar a explicação de Stein (acima), o termo "prática" encerra um sentido de "condição de possibilidade de todas as experiências" (STEIN, 2004, p. 31).

Tendo em vista a especificidade do sentido que a palavra "prática” recebe no contexto heideggeriano, não significa que haja nesse caso uma fronteira radical entre prática e teoria (conforme se da na acepção da tradição filosófica). Ser e tempo não desenvolve, definitivamente, uma polarização entre teoria e prática.

No tocante ao empenho prático do Dasein no mundo, um termo se destaca quanto à sua importância: circunvisão [Umsicht]. Grosso modo, esse termo-chave indica um "olhar prático", "um saber-prático" que o Dasein tem na relação em sua forma mais imediata com os entes intramundanos. Porém tal "saber-prático" não é "ateórico" no sentido de desprovido de visão (ou seja, uma "ação cega"), não se trata de um comportamento prático em que se age contraposto a um comportamento teórico em que se considera (delibera). O conceito heideggeriano de circunvisão, conforme veremos adiante com maior rigorosidade, contempla uma ação que emprega sim certo conhecimento teórico (enquanto um saber-como), quer dizer, trata-se de uma ação portadora de um "conhecimento próprio" (e não perceptivo), já que o ente intramundano com o qual o ser-aí relaciona-se, não é objeto teórico e sim utilizado, empregado etc. Com isso, indica-se que a relação que o Dasein tem com o (ente intramundando que vem ao encontro dentro do) mundo, por assim dizer, não está no sentido teórico-conceitual, mas sim que o Dasein relaciona-se com tais entes, primariamente, de modo a não tematizá-los (a isso se refere a familiaridade originária-prática do ser-aí para com o mundo). Assim sendo, a questão não é evidenciar que Heidegger simplesmente realiza inversão do pensamento moderno (destacando a "relação prática" da "teórica”), ou que o autor supostamente confira primazia à lida prática no mundo em detrimento do teórico; antes, porém, o que está em questão, principalmente, é que o filósofo alemão considera o modo (de ser-no-mundo) teórico-temático como uma derivação do enraizamento ontológico abordado por ele: o já-estar-prático-no-mundo. O esforço de nosso trabalho reside, portanto, em explicitar o mais originário do Dasein, a saber, o lidar prático no mundo, e isso em um sentido de sua condição mais originária de já-estar-no-mundo.

\section{DASEIN: A FAMILIARIDADE PRÁTICO-ORIGINÁRIA NO MUNDO}

A expressão "ser-no-mundo" [in der-Welt-sein] não exprime uma relação de encaixe na qual o Dasein está dentro do mundo. Para Ser e Tempo, o mundo não é um dado que está aí diante de nós, tal qual um receptáculo de objetos. Antes, porém, o Dasein só “é” no - e não dentro do - mundo, de modo que só no mundo ele, enquanto estar-aí, torna-se acessível.

pode parecer que o constructo 'estar-aí' - de certo modo o novo e ao mesmo tempo o mais antigo revelado 
pela analítica existencial - esteja fadado a desempenhar o modelo alternativo para a relação eu-mundo e represente o novo ponto de partida para o conhecimento, sendo o fundamentum inconcussum cartesiano. Entretanto, o ser-no-mundo não é uma instância privilegiada fundadora; o conhecimento - isto é, a compreensão - constitui o mundo já sempre praticamente. A racionalidade que se inangura e que se exerce a partir de Heidegger é prática: já não há mais instância metateorética justificando a teoria; a teoria é uma prática do serno-mundo (STEIN, 2005, p. 27. Grifo nosso)

Quer dizer, a relação subjetividade-objetividade (eu-mundo) de forma alguma equivale ou coincide com Dasein e mundo. Posto que ser-no-mundo é uma constituição fundamental do Dasein em que ele se move, sobretudo, no modo da cotidianidade, então de um jeito ou de outro Dasein já deve ter se familiarizado com o mundo. Ainda consoante à citação de Ernildo Stein, conhecer é um modo de ser do Dasein que, enquanto atividade ôntica, funda-se precisamente em sua constituição ontológica, isto é, tem seu fundamento "num já-ser-junto-ao-mundo, no qual o ser do Dasein se constitui de modo essencial" (HEIDEGGER, 1988, p. 100). Diferente do paradigma sujeito e objeto, no qual o sujeito-interioridade encontra-se afastado do mundo-exterioridade, o Dasein não sai de uma esfera interna "encapsulada", ao invés disso, porém, desde sempre esteve "fora", junto ao ente a ser apreendido e "no" mundo por isso mesmo de alguma forma descoberto. Além disso, ao deter-se junto ao ente intramundano a fim de (tematicamente) conhecêlo, o mundo não se "abre" para o Dasein visto que nunca esteve "fechado" para ele.

Mundo é, em si mesmo, um constitutivo do Dasein, de modo que a expressão ser-no-mundo, já em sua composição, dirige-se a um fenômeno de unidade e não de fragmentação de mais de um elemento (o “ser" "no" "mundo"). "Do ponto de vista ontológico, 'mundo' não é determinação de um ente que o Dasein em sua essência não é. 'Mundo' é um caráter do próprio Dasein” (HEIDEGGER, 1988, p. 105). Neste sentido, não há Dasein sem mundo (pois só "é” no mundo) e não há mundo sem Dasein (visto que mundo é o próprio caráter do Dasein).

Mundanidade está exclusivamente como adjetivo do modo de ser do Dasein, diferente das entidades desprovidas da estrutura do "ser-no-mundo", que estão na verdade "dentro" do mundo. Na obra de 1927, Ser e Tempo, o sentido de estar "dentro de" caracteriza tão somente a determinação categorial do ente intramundano, cujo modo de ser está num outro, como a água está no copo, a roupa está no armário, a sala está na universidade. "Esses entes, que podem ser determinados como estando um 'dentro' do outro, têm o mesmo modo de ser do que é simplesmente dado, como coisa que ocorre 'dentro' do mundo" (HEIDEGGER, 1988, p. 91-2). Verifica-se, porém, que a disposição categorial é ontologicamente diversa do Dasein e não se aplica a ele (os caracteres ontológicos do Dasein são chamados por Heidegger de modalidades existenciais, ao passo que as determinações ontológicas dos entes intramundanos diferenciam-se como modalidades categoriais). Não se trata aqui de "um commercium simplesmente dado entre um sujeito simplesmente dado e um objeto simplesmente dado" (HEIDEGGER, 1988, p. 186). Em visto do exposto, conclui-se que ser-em [In-Sein] não indica justaposição de interioridade de um "sujeito" (simplesmente dado) dentro do "mundo" (simplesmente dado), mas, isso sim, revela que Dasein está desde sempre junto-ao-mundo. Do ponto de vista ontológico, essa justaposição meramente categorial explode, desvirtua e fragmenta o fenômeno originário ser-no-mundo, tal como se observou no modo "tradicional de tratar o "problema do conhecimento" (HEIDEGGER, 1988, p. 186). Ser-em designa por excelência uma constituição existencial, portanto, nada tem a ver com uma relação espacial de estar dentro. $\mathrm{Na}$ verdade, ao trazer a definição terminológica originária da expressão, Heidegger utiliza o termo pensando no sentido de estar "habituado a", estar "familiarizado com", estar "acostumado a".

Assim, a relação mais primária que o Dasein trava com o mundo não é da ordem contemplativa, no 
sentido de relação cognoscitiva. O mundo que preliminarmente se apresenta ao Dasein é o da práxis cotidiana, da ação prática, isto é, o mundo circundante, no qual o ser-aí manifesta uma relação instrumental com os entes intramundanos que servem para isso ou para aquilo. Ou seja, o mundo que preliminarmente Heidegger focaliza é o mundo circundante que, por sua vez, constitui-se pelo para quê [Wozu] do instrumento disponível [Zuhanden] à ocupação do Dasein como um ente à mão. Dasein só é como é, sendo-no-mundo, de modo que os entes não-existentes, isto é, os categoriais, só podem deparar-se com ele na medida em que se mostram, por si mesmos, dentro do mundo circundante, no qual o Dasein apresenta atitude primordialmente prática.

O que é o mundo? Em Ser e tempo Heidegger aborda esta questão através de uma interpretação das operações cotidianas do Dasein. "Para se ver o mundo é, pois, necessário investigar o ser-no-mundo cotidiano em sua sustentação fenomenal” (HEIDEGGER, 1988, p. 107). Não obstante, considerar o ser-nomundo cotidiano é o mesmo que considerar seu modo de lidar com os entes intramundanos, isto é, o modo de lidar com os entes que primeiro vêm ao encontro. Para tanto, o autor traz à tona o mundo mais próximo do Dasein (dentro do qual os entes intramundanos primariamente vêm ao encontro), a saber: mundo circundante [Umwelt]. No mundo circundante o Dasein desenvolve determinado tipo de relação caracterizado por Heidegger como ocupação no manuseio e uso; de acordo com GünterFigal: “'Ocupação' é aqui um termo que designa um 'modo de ser' do 'ser-no-mundo', a saber, todas as maneiras de comportar-se que apontam para uma lida com um ente, que não se mostra como 'ser-aí"' (FIGAL, 2005, p. 73). Quer dizer, trata-se das relações: o fazer com alguma coisa, produzir alguma coisa, empreender, construir, consertar, etc. Assim sendo, o Umwelt, segundo Inwood (2002, p. 121) tão central em Ser e tempo, diz respeito ao mundo à nossa volta, ao mundo familiar ao Dasein e que desde sempre ele de alguma forma o compreende ${ }^{1}$; neste caso, mundo circundante assume um sentido ôntico já que se refere ao contexto imediato em que "vive" o Dasein de início e na maioria das vezes. Enquanto condição ontológica fundamental de ser-no-mundo, Dasein está originariamente habituado com esse contexto em que desde sempre ele se compreende.

Com efeito, faz-se necessário destacar que quando Heidegger utiliza o termo compreensão [Verstehen], vale ressaltar que não se trata de uma compreensão de ordem teórico-conceitual e sim no sentido de familiaridade prático-originária com o mundo (condição pré-reflexiva e pré-teórica). "Tal familiaridade com o mundo não exige, necessariamente, uma transparência teórica das remissões que constituem o mundo como mundo" (HEIDEGGER, 1988, p. 131). Ou seja: no mundo circundante o Dasein se relaciona com o ser dos entes que vêm ao encontro, isto é, relaciona-se apenas com o modo de ser dos entes disponíveis, estes entes disponíveis, porém, não estão na condição de objeto teórico, mas, isto sim, estão enquanto aquilo que é utilizado, produzido, fabricado, empregado, entre outros. Quer dizer, o ente que nesta condição vem ao encontro é visualizado pelo Dasein de forma pré-temática, através de um “conhecimento" que não visa as propriedades entitativas de determinado ente, mas sim sua serventia prática que se encontra implicada com todo um contexto.

Por exemplo, quando se manuseia uma "caneta", o ente em questão já se revelou de alguma forma (mesmo que não de modo temático) para o Dasein. Ledo engano, porém, concluir que a caneta está considerada (isoladamente) por si e em si mesma, enquanto "coisa" pontiaguda com a propriedade tinta esferográfica cuja "essência” pode ser apreendida através de uma visualização meramente teórica. Tendo em vista a (pré) compreensão enquanto familiaridade originária que o Dasein tem com o mundo, a caneta só se revela a partir da sua utilidade "para...", quer dizer, só se sabe "para quê" serve uma caneta uma vez que o Dasein

${ }^{1}$ (HEIDEGGER, 1988, p. 91, 97-8,104-5, 106) 
já se encontra com ela e imerso dentro de um determinado contexto instrumental pertinente à serventia da caneta (a caneta só pode ser o que ela é dentro de um contexto instrumental).

Ou seja, sabe-se o "para quê" do ente intramundano em questão quando sua serventia (isto é: sua utilidade) faz sentido dentro de um contexto pertinente (a serventia de uma caneta tem sentido se relacionada, por exemplo, com papel, caderno, mesa, cadeira, lâmpada, janela, sala). A caneta, assim sendo, apresenta-se tal como é conforme a pertinência de outros instrumentos, quer dizer, ela corresponde a sua "canetalidade" a partir do "algo para..." conforme a pertinência de outros instrumentos: a "caneta" é para escrever no "papel", para registrar no "caderno", para estudar na "mesa", para ler sob a "lâmpada", para ... . De certa forma isso equivale a afirmar que a "essência" (o "ser-em-si") de um instrumento reside em "algo para..." (algo que se refere a...) - numa palavra, a caneta revela ela mesma seu "ser-em-si" no próprio ato de sua utilização que se encontra entrelaçado com um contexto instrumental.

Em vista disso, evidencia-se, com Ser e tempo, que a "essência" de um instrumento reside em "algo para...", reside nos estruturais modos de "ser para", os quais dizem respeito precisamente à referência de algo para algo: "O ser do manual tem a estrutura da referência”" (HEIDEGGER, 1988, p. 128). Assim, referência está relacionada ao modo de ser do instrumento que consiste em "algo para...”, isto é, de algo que se refere para algo. Grosso modo isso significa: o instrumento em questão possui, em si mesmo, o caráter de estar referido a...: "O ente se descobre na medida em que está referido a uma coisa como o ente que ele mesmo é" (HEIDEGGER, 1988, p. 128). Quer dizer, um instrumento corresponde a seu modo de "ser para" a partir da pertinência de estar referido a outro instrumento.

Com isso, busca-se destacar esse caráter ontológico do instrumento que é chamado por Heidegger (1988, p. 128) de conjuntura [Bewandtnis]. Ser e Tempo reserva esse termo para caracterizar o movimento segundo o qual "algo se deixa e faz junto", precisamente ligado ao caráter ontológico do instrumento de (se deixar e se fazer) junto a algo. Como diz Heidegger (1988, p. 128): “Conjuntura é o ser dos entes intramundanos em que cada um deles já, desde sempre, liberou-se”.

Ademais, ainda no tocante ao termo conjuntura e seu caráter de "deixar e fazer algo" junto à algo, Günter Figal observa:

a conjuntura não diz o que algo é, mas como o que ele é.[...] Ele [algo manual] só se deixa interpretar 'como algo' quando o 'deixamos ser', de modo que a realização da interpretação nunca pode ser pensada senão conjuntamente com um deixar (FIGAL, 2005, p. 77. Grifos do autor).

Conforme os SS 15 a 18 de Ser e tempo indicam, o aspecto constitutivo e ontológico caracterizado como conjuntura do instrumento, isto é, "algo se deixa e faz junto" (à algo), está ligado ao para quê da serventia desse instrumento - instrumento que, por sua vez, aponta para outro no seu para quê, que também, por sua parte, aponta sucessivamente para outro instrumento, de modo a formar uma trama de mútuas remissões. Deixar ser e fazer junto significa liberar o ente para uma totalidade conjuntural [Bewandtnisganzheit]. Por exemplo, o "deixar ser e se fazer junto" do manual que se nomeou "caneta" possibilita um todo conforme a pertinência de outros manuais, isto é, possibilita uma conjuntura: "caneta" para escrever no "papel”, para registrar no "caderno", para estudar na "mesa", para ler sob a "lâmpada", para ... .

Indo além, nota-se que o mundo do Dasein não é de âmbito solipsista ou restrito a uma suposta criação subjetiva. Mundo é contexto, e contexto com-partilhado no qual se libera os outros Dasein para que assim vem ao encontro neste contexto. Ser-no-mundo envolve seres-no-mundo. Segundo Dicionário Heidegger (INWOOD, 2002, p. 120-1): 
O mundo é introduzido por meio do Umwelt familiar, e o ser-no-mundo mantém um tom de familiaridade, de saber seu próprio caminho no mundo. As coisas se entrelaçam, formando um mundo unificado pela significação: os instrumentos que usamos referem-se a outros instrumentos, que juntos formam um local de trabalho, por sua vez referido ao mundo mais amplo além do local de trabalho. O martelo do artesão refere-se aos seus pregos, à madeira e ao couro, e ao banco no qual ele trabalha; além do local de trabalho estão seus clientes, as vacas que fornecem o couro, a floresta que fornece a madeira, e desta forma expandem-se indefinidamente círculos de familiaridade cada vez mais remota.

Com isso, Inwood refere-se à descrição heideggeriana do mundo circundante mais próximo do $D a$ sein que, em última instância, traz à tona outros entes, neste caso: os existentes. Por exemplo, o mundo do produtor de canetas. Ao fabricar o mencionado ente, faz-se necessário articular-se também com sua conjuntura, isto é, com seu entorno instrumental pertinente ao ente caneta. Com isso, também vem ao encontro outros entes com os quais a "obra" se destina ou demanda: junto com o material empregado, também vem ao encontro o seu produtor e/ou fornecedor; o local, por exemplo, onde se produz propriamente o objeto em questão, mostra-se como local que pertence a alguém, alugado a outrem; a caneta fabricada é vendida em tal lugar que pertence a tal comerciante; ao fabricar tal objeto, visa-se para qual tipo de pessoa pretende vender... e assim por diante. Assim, Heidegger diz: "O próprio Dasein, bem como o co-Dasein dos outros, vem ao encontro, antes de tudo e na maior parte das vezes, a partir do mundo compartilhado nas ocupações do mundo circundante" (HEIDEGGER, 1988, p. 178). O que está em jogo é: a partir de um mundo circundante "os outros" que vêm ao encontro do Dasein não se restringem apenas ao instrumento manual (e à natureza simplesmente dada), mas, também, os entes cujo modo de ser é o do Dasein.

O mundo do Dasein libera, portanto, entes que não apenas se distinguem dos instrumentos e das coisas mas que, de acordo com seu modo de ser de Dasein, são e estão 'no' mundo em que vem ao encontro segundo o modo de ser-no-mundo (HEIDEGGER, 1988, p. 169).

Nisso consiste o co-Dasein: o encontro que se dá a partir do mundo em que o Dasein se conserva empenhado em ocupações orientadas pela circunvisão.

Circunvisão - eis um conceito chave do empenho prático do Dasein no mundo.

Não obstante, visto que o Dasein lida com os instrumentos subordinando-se a uma multiplicidade do modo de "ser para", Heidegger denomina a visão dessa subordinação de circunvisão [Umsicht] que, grosso modo, diz respeito a uma visão de conjunto. Daí o lugar do "olhar prático", quer dizer, visão que circunda, abrange e abarca: guiada por uma visão de conjunto, a circunvisão contempla os instrumentos que se entrelaçam e que se articulam formando, em última instância, uma totalidade instrumental (mundo). "A atitude teórica visualiza meramente, sem circunvisão” (HEIDEGGER, 1988, p. 111). Assim, a ocupação demanda um "conhecimento próprio" (e não perceptivo), já que o ente aqui não é objeto teórico e sim fabricado, empregado etc. O manuseio designa o ente intramundano em sua forma mais imediata, e por isso mesmo mais primária que qualquer concepção teórica.

Com isso, conclui-se que a compreensão que desde sempre o Dasein tem do (ente intramundando que vem ao encontro dentro do) mundo, por assim dizer, não está no sentido teórico-conceitual, mas sim em termos de familiaridade originária-prática com o mundo (se des-cobre e se des-oculta o ser do ente caneta no próprio ato da ocupação de escrever no papel, que está em um caderno, que está em cima da mesa, sob 
a iluminação da lâmpada etc, que em última instância está em função, por exemplo, de pesquisar)². Nota-se, portanto, a primazia do empenho prático-originário do Dasein na lida com o ente disponível; quanto a isso, vale trazer à luz a precisa observação de Ernildo Stein:

A racionalidade que Heidegger procura desenvolver se apoia no segundo modo fundamental de ser do estar-aí: o lidar com o ente disponível, modo que situa o homem no mundo, através de um compreender que antecede a compreensão teórica e sua explicitação pela enunciação: o 'como hermenêutico' que funda o 'como aponfântico' (STEIN, 2005, p. 78)

Consoante à citação de Stein, nota-se, em relação ao estar-aí, a primazia de um lidar prático - em termos de familiaridade originária - no mundo. Ademais, a partir da investigação da compreensão enquanto familiaridade originária com o mundo, deve-se destacar a posição heideggeriana segundo a qual compreender é mais originário que interpretar: interpretar é interpretar um mundo já compreendido. Com efeito, a interpretação só apreende uma conjuntura já de muito aberta pela compreensão, de modo que como se interpreta é o como se abre na compreensão. "Toda interpretação que se coloca no movimento de compreender já deve ter compreendido o que se quer interpretar” (HEIDEGGER, 1988, p. 209). Toda interpretação, segundo Heidegger (1988, p. 209), possui posição prévia [Vorhabe], visão prévia [Vorsicht] e concepção prévia [V orgriff]: o filósofo alemão denomina esse conjunto de pressuposições de situação hermenêutica. Ou seja, a interpretação funda-se, alimenta-se e move-se numa compreensão primária e originária, não oferecendo, portanto, nenhuma explicitação isenta de pressuposições. Interpretar significa explicitar o já previamente compreendido.

A compreensão está para a interpretação como estrutura originária fundante, todavia, deve-se sublinhar, por outro lado, que a compreensão funda mas não se desvincula da interpretação, de modo que não há compreensão sem interpretação. Com isso, Martin Heidegger ressalta uma repercussão circular ${ }^{3}$ entre $^{-}$ ambos os conceitos, uma vez que a interpretação se dá na abertura compreensiva e ao mesmo tempo é precisamente a interpretação que permite a compreensão apropriar-se do compreendido. $\mathrm{Na}$ interpretação, “a compreensão se apropria do que compreende. Na interpretação, a compreensão se torna ela mesma e não outra coisa” (HEIDEGGER, 1988, p. 204). Desse modo, nota-se a articulação intrínseca desses dois conceitos-chave, compreensão e interpretação (que, diga-se de passagem, compõem o título do $\int 32$ de Ser

2 Ser e Tempo indica que a própria totalidade conjuntural (caneta-papel-caderno-mesa-lâmpada-etc), em última instância, também remonta a um para quê, agora, porém, não mais ligado a um ente cujo modo de ser é o de disponibilidade, na verdade trata-se de um para quê primordial que está ligado a um ente cujo ser se determina, isto sim, como ser-no-mundo, ou seja, cujo ser é essencialmente mundano. "O para quê (Wozu) primordial é um estar em função de. 'Em função de', porém, sempre diz respeito ao ser do Dasein que, em sendo, está essencialmente em jogo seu próprio ser" (HEIDEGGER, 1988, p. 129). Assim, observa-se que o para quê primordial sempre está em função do ser do Dasein (caneta-papel-caderno-mesa-lâmpada-etc..., em função de estudar, pesquisar).

3 Em vista da repercussão circular entre compreensão-interpretação, Heidegger é considerado segundo os critérios das regras mais elementares da lógica (HEIDEGGER, 1988, p. 209) de cair em um "círculo vicioso". Ora, como a interpretação já sempre se movimenta no já compreendido, como poderá interpretar sem se mover num círculo? Para Heidegger, “ver nesse círculo um vício, buscar caminhos para evitá-lo e também 'senti-lo' apenas como imperfeição inevitável, significa um mal-entendido de princípio acerca do que é compreensão" (HEIDEGGER, 1988, p. 210. Grifos do autor). A interpretação se apresenta mediante aquilo que é preliminarmente dado na posição prévia, visão prévia e concepção prévia, não se apresentando, portanto, como uma apreensão pura ou isenta (HEIDEGGER, 1988, p. 207). Assim, considerar esse círculo como "vicioso" é o mesmo que desconsiderar as condições fundamentais de uma interpretação possível e as condições essenciais de sua realização. Adjetivar tal círculo como "vicioso" significa descartar a possibilidade do conhecimento mais originário do único ente que interpreta porque compreende e se apropria de forma compreensiva porque interpreta. 
e tempo).

Toda visão pré-predicativa do que está à mão já é em si mesma uma compreensão e interpretação. [...] O ver dessa visão já é sempre compreensão e interpretação. Já traz em si a explicitação das remissões referenciais (do ser-para) constitutivas da totalidade conjuntural, a partir da qual se entende tudo que simplesmente vem ao encontro (HEIDEGGER, 1988, p. 205).

Com isso, conclui-se que o Dasein, no mundo circundante, possui uma (pré) compreensão dos instrumentos na qual eles ainda não são tematizados - o que está em jogo aqui: "compreender uma situação assim como ela é 'dada', antes mesmo de a tornar tema da investigação ou reflexão" (SAFRANSKI, 2000, p. 136). O Dasein lida com tais instrumentos enquanto um saber-prático, e a interpretação, neste sentido, é justamente aquilo que indica que “ele é para...”: “O 'como' constitui a estrutura da explicitação do compreendido; ele constitui a interpretação" (HEIDEGGER, 1988, p. 205).

Assim, a compreensão, "por nós caracterizada como existencial básico do Dasein" (HEIDEGGER, 1988, p. 207), reside no lidar prático-originário com um ente intramudano, por exemplo, chamado "caneta" e, dessa forma, funda a interpretação a qual "vê" a caneta enquanto "algo para..." isto é, de algo que se refere para algo.

\section{A DEFINIÇÃO DO ENTE HUMANO COMO CURA}

Com efeito, pretende-se neste item evidenciar a primazia da postura prática do Dasein, consoante à proposta de nosso texto, ao trazer à tona a estrutura mais originária do Dasein, a saber: o fenômeno da cura [Sorgen]. Com a explicitação desta estrutura mais básica e elementar do Dasein, destaca-se a atitude do ente que nós mesmos somos como primariamente "prática", e não cognitiva ou teórica. Segundo Stein, "É a partir da definição do homem como cuidado que Heidegger nos provoca a recolocar a questão das ciências humanas num contexto vinculado a uma espécie de cogito prático" (STEIN, 2005, p. 100). Nota-se, assim, como a perspectiva heideggeriana, ao se debruçar sobre a atitude do ente humano - homem ou mulher para com o mundo, diferencia-se radicalmente de uma perspectiva que confere primazia à atitude cognitiva ou teórica.

Em sua essência, o ser-no-mundo é cura. Isso equivale afirmar que a cura é a totalidade originária mais básica e elementar da estrutura do Dasein: “a cura se acha, do ponto de vista existencial, a priori, 'antes' de toda 'atitude' e 'situação' do Dasein, o que sempre significa dizer que ela se acha em toda atitude e situação de fato" (HEIDEGGER, 1988, p. 258. Grifos do autor). Considerando justamente que a cura se acha, do ponto de vista existencial, a priori, isto é, antes de toda atitude do ente humano, pode-se concluir, com Heidegger, que o fenômeno da cura abrange a unidade das determinações ontológicas de ser-junto-aomundo (ocupação) e ser-com (preocupação). Isto é, cura [Sorgen] é a totalidade originária mais básica da estrutura do Dasein, a ponto de comportar suas atividades no mundo [Besorgen] e o seu ser-com-outros [Fürsorge].

Neste sentido, já que a cura designa a interação mais elementar que o ente humano estabelece com seu ser, tal observação distingue a visão heideggeriana daquela que considera a atitude do ente humano para com o mundo como primariamente cognitiva e teórica. Neste sentido, trata-se de uma cura ocupada-preocupada [Besorgend-Fürsorgende Sorge], de modo que que quando usamos simplesmente o termo "cura" já nos 
referimos à [i] ocupação e [ii] à preocupação. Vejamos.

[i] Conforme procurou-se explicitar na primeira parte de nosso trabalho, a ocupação, por sua vez, é guiada não pelo conhecimento teórico, mas pelo seu "prático" saber-como. Procurou-se explicitar que no mundo circundante o Dasein relaciona-se pré-compreensivamente com os entes que vem ao encontro. Compreensão, neste sentido, indica não uma tematização teórica de tais entes, mas sim a familiaridade-prática que o Dasein tem com o mundo. Neste sentido, a ocupação, em última instância, implica justamente em um saber-prático do Dasein.

[ii] Por outro lado: “A palavra mágica pela qual de repente Heidegger faz o cotidiano e habitual aparecer como que transformado é: preocupação [Sorge]” (SAFRANSKI, 2000, p. 150). Preocupação indica uma lida mais "prática" ainda, na medida em que indica uma relação com os outros em que há consideração [RücksichA]. Isso no sentido de um contínuo cuidar ("prático") de outrem, conforme comenta Benedito Nunes (1992, p. 97), que inclui tanto as formas negativas (hostilidade, aversão) quanto as positivas (amor, dedicação). O cuidar-se com uma alimentação saudável, com exercício físico, tratar do corpo doente - tudo isso se dá enquanto pre-ocupação. Deste modo, procurou-se destacar o caráter mais básico e elementar da cura, ao explicitar o empenho veementemente prático presente nos modos "ocupação" e "preocupação", os quais são, por excelência, constitutivos da cura.

Com isso, ressalta-se a cura como estrutura mais originária e primária do Dasein, visto que ela considera a atitude do ente humano, homem ou mulher, para com o mundo como primariamente "prática", e não cognitiva ou teórica. Neste raciocínio, Ernildo Stein observa: “O cuidado [cura] define o homem como ser-no-mundo em sua estrutura prática" (STEIN, 2005, p. 95).

Ademais, evidencia-se o caráter eminentemente prático da estrutura ontológica cura, sobretudo levando-se em conta o recurso extremamente decisivo que Heidegger traz à tona de um testemunho préontológico segundo o qual o Dasein se descobre de "modo originário". Trata-se de uma antiga fábula latina do século $\mathrm{V}$, na qual se narra a criação do homem"

Certa vez, atravessando um rio, 'cura' viu um pedaço de terra argilosa: cogitando, tomou um pedaço e começou a lhe dar forma. Enquanto refletia sobre o que criara, interveio Júpiter. A cura pediu-lhe que desse espírito à forma de argila, o que ele fez de bom grado. Como a cura quis então dar seu nome ao que tinha dado forma, Júpiter a proibiu e exigiu que fosse dado o [seu] nome. Enquanto 'cura' e Júpiter disputavam sobre o nome, surgiu também a terra (tellus) querendo dar o seu nome, uma vez que havia fornecido um pedaço de seu corpo. Os disputantes tomaram Saturno como árbitro. Saturno pronunciou a seguinte decisão, aparentemente equitativa: 'Tu, Júpiter, por teres dado o espírito, deves receber na morte o espírito e tu, terra, por teres dado o corpo, deves receber o corpo. Como, porém, foi a 'cura' quem primeiro o formou, ele deve pertencer à 'cura' enquanto viver. Como, no entanto, sobre o nome há disputa, ele deve se chamar 'homo', pois foi feito de humus (terra) (HEIDEGGER, 1988, p. 263-4. Grifo nosso).

Explicitamente Heidegger toma a cura como primazia mais elementar e originária do Dasein. Primeiramente, isso pelo fato de o Dasein estar ligado a ela enquanto viver, que aqui podemos traduzir como a constatação de que o ente que nós somos comporta-se com seu ser colocando-o em jogo, isto é: em sendo. Visto que o ente que nós somos comporta-se com seu ser colocando-o em jogo (em sendo), então a

4 "Sem entrar nos detalhes históricos de como surgiu esta alegoria, lembremos apenas que se trata de uma velha fábula que entre as Fábulas de Higino está registrada com o número 220 e traz o título Cura. Heidegger encontrou informações sobre esta fábula num texto de Konrad Burdach. Este por sua vez mostra que Goethe se informou sobre esta fábula a partir de um poema de Herder e desta maneira a incluiu, na figura de uma anciã, na segunda parte do Fausto" (STEIN, 2005, p. 98) 
"essência" deste ente só pode consistir em ter de ser, ou melhor, em ter de existir a fim de determinar a possibilidade que o Dasein é; ou, dito o mesmo de forma literal: "A delimitação da estrutura da cura forneceu as bases para uma primeira distinção ontológica entre existência e realidade. Isso levou à seguinte tese: a substância do homem é a existência” (HEIDEGGER, 2005, p. 107). Neste raciocínio, este ente não possui uma "natureza" primordial, já que sua essência, na medida em que se possa falar dela, consiste precisamente na interação cuidadosa deste ente com seu ser. A totalidade estrutural do Dasein desentranha-se como cura. Nela, tem-se a relação mais originária entre Dasein e seu ser, tendo em vista que a análise desse ser, segundo Ser e tempo, tem como fio conductor a existência - que é a essência do Dasein. Quer dizer: o Dasein "é" o que, em sendo, está em jogo seu próprio ser.

Ademais, observa-se que essa primazia da cura emerge diante de (e contra) uma concepção que considera o homem como animal racional (na qual ele é apreendido como o composto de corpo e espírito). Neste sentido, destaca-se a precisa corroboração de Ernildo Stein:

Com a definição do homem como cuidado, Heidegger quer encontrar uma estrutura prática que ele chamará de estar-no-mundo, numa espécie de confronto com o destaque teórico que aparece na definição tradicional do homem. Mas esta definição tradicional, racionalista, é substituída porque ela tem, não apenas consequências sobre a concepção de realidade (ontologia) e de conhecimento (epistemologia), colocando o homem como uma espécie de máquina mental cognitiva diante do mundo e da verdade. É sobretudo dos pressupostos que se trata na crítica heideggeriana à definição tradicional. Quais são estes pressupostos? É que para definir o homem como animal rationale foi preciso realizar um longo caminho metafísico marcado pelo dualismo platônico. É justamente contra esta tradição dualista e sua consequências para a definição do homem que se volta o projeto da analítica existencial (STEIN, 2005, p. 95).

Assim sendo, o ente humano “possui a ‘origem’ de seu ser na cura” (HEIDEGGER, 1988, p. 264), e permanecerá ligado a esse origem enquanto for e estiver no mundo. Diante disso, levar em conta, do ponto de vista ontológico, a petrificada concepção de homem como animal racional é o mesmo que encobrir, por assim dizer, o que há de mais originário e elementar no ente humano: sua interação cuidadosa com seu ser. E mais. As epistemologias que assim procedem, "não são deficientes quanto à epistemologia [propriamente] mas que, devido ao descaso da analítica existencial do Dasein, elas não podem absolutamente conquistar o solo para uma problemática segura de suas bases” (HEIDEGGER, 1988, p. 273).

Ao cabo, pretende-se encaminhar o presente trabalho para suas conclusões finais. Para tanto, não se pode deixar de sinalizar, antes, uma ressalva. De alguma forma buscou-se evidenciar, por um lado, que Heidegger marca a diferença de sua perspectiva quanto à relação "prática" do Dasein no mundo. Por outro lado, porém, isso não significa que ele o faz em detrimento de uma postura teórica-temática do Dasein a fim de descartar tal postura como "inferior" ou "errônea".

As vias interpretativas as quais Heidegger confronta em Ser e tempo, de acordo com as quais a atitude teórica designa o primordial (quiçá, o a priori) do ente humano - homem ou mulher -, em nenhum momento deste tratado incompleto de 1927 Heidegger as tomou como incorretas ou falsas, que devem ser veementemente refutadas. O que está em questão, principalmente, é que o filósofo alemão considera o modo (de serno-mundo) teórico-temático como uma derivação do enraizamento ontológico abordado por ele: o já-estarprático-no-mundo. Na segunda seção de Ser e tempo o autor assinala: "toda questão, ontologicamente explícita, sobre o ser do Dasein já se acha preparada pelo próprio modo de ser do Dasein” (HEIDEGGER, 2005, p. 105). Heidegger considera, sim, como importante a compreensão enquanto campo teórico (esclarecimento), próprio do âmbito cognitivo - e tem até sua relevância na analítica existencial empregada em Ser 
e tempo; contudo, a questão é que se trata de uma derivação existencial de um sentido mais originário e primário de compreensão. Aliás, qualquer forma de conhecimento é uma derivação da compreensão mais originária do Dasein: “'Intuição’ e ‘pensamento’ já são ambos derivados distantes da compreensão” (HEIDEGGER, 1988, p. 203).

Portanto, nota-se, preliminarmente, que questões que contextualizam a postura teórica como primordial do ente humano são, de fato, válidas para Martin Heidegger, desde que remetidas adequadamente à raiz originária do empenho prático-originário do Dasein na lida com o mundo. Por isso que, consoante à proposta do presente trabalho, buscou-se enfatizar, do ponto de vista da investigação de Heidegger, o termo “originário", pois o que está em questão é que qualquer compreensão teórica que Dasein tem do mundo não passa de algo derivado, fundado de sua condição mais originária de já-estar-no-mundo. A compreensão pré-teórica do Dasein, numa palavra, é mais originária do que qualquer conbecimento cognitivo.

\section{CONSIDERAÇÕES FINAIS}

Pretendeu-se explicitar a forma originária de Martin Heidegger de abordar a lida mais primária do Dasein no mundo, cuja primazia recai em um sentido prático. Procurou-se explicitar que a relação mais primária que o Dasein trava com o mundo não é da ordem contemplativa, no sentido de relação cognoscitiva. O mundo que preliminarmente se apresenta ao Dasein é o da práxis cotidiana (da ação prática), isto é, o mundo circundante, no qual o ser-no-mundo, através da circunvisão (cujo sentido assume um "olhar prático" para os instrumentos que se entrelaçam), manifesta uma relação instrumental com os entes intramundanos que servem para isso ou para aquilo. Além disso, buscou-se ressaltar a compreensão do Dasein em termos de familiaridade prático-originária com o mundo (condição pré-reflexiva e pré-teórica) que, justamente por isso, empenha-se em uma lida prática com o ente disponível - só se sabe "para quê" serve determinado ente intramundano uma vez que o Dasein já se encontra com ele e imerso dentro de um determinado contexto instrumental pertinente à serventia deste ente. Ao cabo, evidenciou-se a definição do ente humano como cura. Tendo em vista esta como a estrutura mais originária e elementar do Dasein, corrobora-se, consoante ao escopo do presente texto, a atitude do ente que nós mesmos somos como primariamente "prática", e não cognitiva-teórica - sendo esta última não "inferior" ou "errônea", mas, sim, derivada, fundada, portanto, não fundamental da constituição humana.

Registro meus agradecimentos aos pareceristas anônimos que, por meio de indicações e comentários, contribuiram para o aprimoramento final do artigo.

\section{REFERÊNCIAS}

DESCARTES, R (1641). Meditações metafísicas. 2. ed. São Paulo: Martins Fontes, 2005.

FIGAL, G (2000). Martin Heidegger: fenomenologia da liberdade. Trad. Marco Antônio Casanova. Rio de Janeiro: Forense Universitária, 2005.

HEIDEGGER, M (1927). Ser e Tempo - parte I. trad. Márcia de Sá Cavalcanti. 2. ed. Petrópolis: Vozes, 1988.

(1927). Ser e Tempo - parte II. Trad. Marcia Sá Cavalcanti Schuback. 12. Ed. Petrópolis: 
Vozes, 2005.

INWOOD, M (1999). Dicionário Heidegger. trad. Luísa Buarque de Holanda. Rio de Janeiro: Jorge Zahar, 2002.

MORA, F (1994). Dicionário de Filosofia - tomo I a IV. Trad. Maria Gonçalves, Adail Sobral, Marcos Bagno, Nicolás Campanário. São Paulo: Loyola, 2000.

NUNES, B (2002). Heidegger \& Ser e Tempo. 2. Ed. Rio de Janeiro: Jorge Zahar, 2004. 1992. (1986). Passagem para o poético - filosofia e poesia em Heidegger. 2. ed. São Paulo: Ática,

SAFRANSKI, R (1999). Heidegger - um mestre da Alemanha entre o bem e o mal. Trad. Lya Luft. São Paulo: Geração Editorial, 2000.

STEIN, E (1990). Seis estudos sobre 'Ser e tempo'. 3. Ed. Petrópolis: Vozes, 2005(1988). Mundo Vivido - das vicissitudes e dos usos de um conceito de fenomenologia. Porto Alegre: EDIPUCRS, 2004.

(1990). Seis estudos sobre 'Ser e tempo'. 3. Ed. Petrópolis: Vozes, 2005.

Artigo recebido em: 31 de maio de 2019

Artigo aceito em: 17 de julho de 2019 